\section{Out of focus}

\author{
Michael Grubb
}

Global Environmental Change: Human and Policy Dimensions. Editor J. K. Mitchell. Butterworth-Heinemann. 4/yr. Europe $£ 110$, elsewhere $£ 115$.

THE first issue of this journal describes its role as being "to balance the discourse on global change" by giving special attention to the contributions of "social and behavioural science, policy science and environmental management". In this endeavour it shows every sign of becoming a success.

Papers are generally about 6,0009,000 words long, well laid out with good use of footnotes. Some of the papers could have been shorter, but in general they present new and relevant information and analysis. No submission dates are given, but the content of the papers suggests reasonably rapid publication. There are no letters or correspondence, but shorter "Viewpoint" articles allow serious debate, the breadth being illustrated by an excellent exchange between one author arguing that climate change will be generally beneficial and another presenting more critical and cautious views. Reports on recent institutional developments, book reviews (rather thin on the ground so far), conference reports and a regular monitoring of relevant activities at the United Nations University provide useful background for any researcher in the area.

Maintaining editorial direction for an interdisciplinary journal is not easy, and the focus of this journal is still somewhat unclear. To my mind, there is a slight preponderance of theoretical socialscience papers, with rather fewer on either management science or practical policy analysis and experience; there is also a striking lack of papers addressing economic issues. The journal thus overlaps sporadically with some other journals, notably its sister publications Natural Resources Forum and Environmental Values, as well as with more specialized publications such as Climatic Change.

The early issues are uncomfortably dominated by US authors, but the most recent show a broader reach, although there is still a worrying absence of papers from developing countries. Without any special concessions, the journal will almost certainly be beyond the reach of libraries in these countries, whose future path of development is so crucial to the issues that it addresses.

Michael Grubb is in the Energy and Environmental Programme, Royal Institute of International Affairs, Chatham House, 10 St James's Square, London SW1Y 4LE, UK.

\section{Energy plants}

\section{W. Bernard Betts}

Biomass and Bioenergy. Editors $J$. Coombs, D. O. Hall, R. P. Overend and W. H. Smith. Pergamon. 12/yr. £310.

TODAY'S sources of energy and chemicals centre largely on nonrenewable materials such as coal, natural gas and especially oil. But diminishing reserves of these materials, uncertainties of supply and cost, and worry about carbon dioxide imbalances and pollution caused by the use of these materials have stimulated great interest in renewable resources such as lignocellulosic materials (for example, wood, straw and derivatives) and other plant residues. These are available through natural biomass turnover, farming and forestry, and from municipal wastes and industrial processing.

Biomass and Bioenergy is a new international journal, first published in 1991, which focuses on biomass production and use. The various key areas covered are categorized as biomass (sources, energy and crop production processors), genetic improvement and composition, biological residues (agricultural, forestry, industrial and municipal wastes), bioenergy processes (fermentations, thermochemical conversions, liquid and gaseous fuels, and petrochemical substitutes) and bioenergy use (direct combustion, gasification, electricity production, chemical processes and by-product remediation). Environmental, management and economic aspects of these areas are included in the scope of the journal.

The journal accepts original researchand-development articles, book reviews, conference reports, details of forthcoming meetings, letters to the editor and topics of special interest. Its editorial team consists of 28 international members, mainly from the United States and Europe. There is minor representation of the Middle East, the Far East, India and Africa but, surprisingly, not of South America. Papers so far, however, have had a truly international breadth supporting the editors' recognition of the importance of biomass and bioenergy in both the developed and developing world.

The style and layout of the journal are traditional rather than old-fashioned and its applied stance is immediately obvious from the front cover photographs, which will continue to feature biomass and bioenergy projects. The contents are conveniently listed on the back cover and forthcoming articles detailed inside. Presentation is clear, with a large double-column format, and instructions stood. Speed of publication seems to vary somewhat, although most papers have been accepted within four mounths of receipt.

Biomass and Bioenergy competes with a wealth of quality journals, particularly the established microbiology, biotechnology, chemical and analytical journals, and it will have to maintain its speed of publication and quality of articles if it is to rival them. One might expect its appealing title automatically to attract workers in the field, but with such a wide scope the journal may have difficulty preserving the standards set in the first few issues. Careful editorial management is required.

W. B. Betts is in the Institute for Applied Biology, University of York, Heslington, York YO1 5DD, UK.

\section{Thinking deep}

\section{John Fox}

Minds and Machines: Journal for Artificial Intelligence, Philosophy, and Cognitive Science. Editor James H. Fetzer. Kluwer. 4/yr. DFI360 (institutional), DFI90 (personal/members).

ABOUT 20 years ago, $I$ found myself in discussion with a prominent epistemologist. Being rather keen on artificial intelligence (AI), I asked him whether he found developments in that field of any interest. He was perfectly courteous, but left me in no doubt that AI was irrelevant to serious philosophical thought. I was astonished. In its distinctive way, AI was deeply concerned with mind, perception, purpose, knowledge and all that stuff you expect to find in philosophical discussions.

Admittedly the subject was still finding its feet just then. It had a tendency to ad hoc methods of enquiry (its methodology was sometimes referred to as experimental programming), and a blithe disregard for what investigators in other disciplines might have to offer.

However, AI has changed considerably in the period since that conversation. Most strikingly, the dominant paradigm now seems to be mathematical rather than experimental. AI routinely applies formal frameworks to its many areas of enquiry; language processing, machine vision, reasoning, decision making, learning, the representation of knowledge - indeed most of its major areas of research.

This may explain why I now find myself reviewing the journal Minds and Machines, whose editorial statement in volume 1 , number 1 indicates that the journal's focus is "philosophical aspects 